\title{
Primary schooling in sub-Saharan Africa: Recent trends and current challenges
}

Cynthia B. Lloyd

Population Council

Paul C. Hewett

Population Council

Follow this and additional works at: https://knowledgecommons.popcouncil.org/departments_sbsr-pgy

Part of the Demography, Population, and Ecology Commons, Family, Life Course, and Society Commons, Gender Equity in Education Commons, and the International Public Health Commons How does access to this work benefit you? Let us know!

\section{Recommended Citation}

Lloyd, Cynthia B. and Paul C. Hewett. 2003. "Primary schooling in sub-Saharan Africa: Recent trends and current challenges," Policy Research Division Working Paper no. 176. New York: Population Council. 
Primary Schooling in sub-Saharan Africa: Recent

Cynthia B. Lloyd

Paul C. Hewett 


\title{
Primary Schooling in sub-Saharan Africa: Recent Trends and Current Challenges
}

\author{
Cynthia B. Lloyd \\ Paul C. Hewett
}

Cynthia B. Lloyd is Director of Social Science Research and Paul C. Hewett is Research Associate, Policy Research Division, Population Council.

We acknowledge the important contribution of Carol Kaufman, our coauthor on previous work on African education. We are grateful to John Bongaarts and Nelly Stromquist for comments on an earlier draft. Funding for this study was provided by the U.K. Department for International Development, The William and Flora Hewlett Foundation, and the Andrew W. Mellon Foundation. 


\begin{abstract}
At the dawn of the twenty-first century we estimate that more than 37 million young adolescents aged 10-14 in sub-Saharan Africa will not complete primary school. Our estimates are based on data from nationally representative Demographic and Health Surveys from 26 countries, collectively representing 83 percent of the sub-Saharan youth population. This number is nearly twice the entire population of children aged 10-14 in the United States, virtually all of whom will complete primary school. Reducing the number of uneducated African youth is a primary objective of the United Nations as laid out in the Millennium Development Goal for education, which sets 2015 as the target year for all children to have completed primary school and for boys and girls to have equal access to education at all levels. Achieving this goal will require a level of international resources and commitment not yet seen; it will also require better tools for monitoring educational progress at the country level. UNESCO draws on enrollment data derived from national management information systems to create two complementary indicators for assessing progress toward universal education: the net primary enrollment ratio and the grade four completion rate. Evaluation of these indicators suggests that they provide, at best, an incomplete and, at worst, a biased picture of levels, trends, and gender differences in school participation and grade attainment. Data from the DHS present a different and, arguably, more realistic picture of trends in schooling and current attendance among sub-Saharan African youth. Whereas steady growth has occurred in attendance and attainment for girls in the last 20 years, educational progress for boys has been stagnant. With the decline in educational disparities between boys and girls, the gap in schooling that remains is between the poorest and the richest households. The gap in schooling delineated by household wealth cannot be monitored even with the best management information systems. It can, however, be captured using household survey data that allow the linking of educational attainment to household economic circumstances. We conclude that current monitoring requirements cannot be fulfilled without substantial new investments in data collection and evaluation.
\end{abstract}

This material may not be reproduced without written permission from the authors. For a list of Policy Research Division Working Papers, including those available for downloading in PDF format, see www.popcouncil.org/publications/wp/prd/rdwplist.html. 
The completion of primary schooling represents a bare educational minimum for today's sub-Saharan African youth as they look forward to at least 40 years of working life in a rapidly changing local and global economy. Given the close link between schooling levels and adult earnings, their economic future and their ability to participate in and contribute to the global economy are primarily dependent on a rise in educational attainment. On the basis of the data presented in this paper, we estimate conservatively that at least 20.8 million or 25 percent of young adolescents aged 10-14 in 2000 have never attended school (11.5 million girls and 9.3 million boys).

Indeed, the level of educational participation and attainment in sub-Saharan Africa falls significantly below that of all other regions in the developing world. Furthermore, in many African countries, rates of growth in primary school completion have flattened out or even declined since the mid to late 1980s. We estimate that for the year 200037.2 million or 45 percent of young adolescents aged 10-14 years in the region will not complete a primary school education. ${ }^{1}$ Because a few large countries dominate the regional average, these estimates mask the results for the worst-performing countries. In many sub-Saharan African countries, less than one-third of adolescents currently complete primary school. Further growth in primary completion rates is necessary for additional educational gains at the secondary level and beyond. A continuing policy priority remains, at a minimum, the achievement of universal primary schooling for girls and boys.

In April 2000 at the World Education Forum in Dakar, Senegal, sub-Saharan African governments, along with governments from around the world, recommitted themselves to achieving Education for All. However, realizing that the target date of 2000 (agreed to in Jomtien, Thailand in 1990) would not be met, the African representatives postponed the realization of this commitment until 2015. During the 1990s, only three African countries came close to achieving Education for All: Malawi, Namibia, and Uganda. Only Kenya, South Africa, and Zimbabwe had achieved that goal before 1990. ${ }^{2}$ The international commitment to Education for All was given a further boost in 2001 when the United Nations General Assembly adopted a road map toward implementation of the U.N. Development Declaration. In its second development goal, the declaration includes a commitment to the achievement of universal completed primary education 
and gender equity in schooling (United Nations General Assembly 2001). Following these international meetings, investments in basic schooling have received heightened attention from donors, governments, and the media because they are seen as a means of alleviating poverty and jump-starting development in countries that had been left behind during the 1990s.

The uncertainty surrounding the state of progress toward educational goals may seem surprising given the recent widespread attention they have received and their universally agreed importance. International population and health targets have been carefully monitored for years by well-funded survey programs, starting with the World Fertility Survey from 1975 to 1984 and continuing with the Demographic and Health Surveys. Progress toward universal primary school completion has been monitored by UNESCO using data collected centrally from national ministries (UNESCO 2002). Previous assessments of UNESCO data, however, raised questions about their comparability and quality (Behrman and Rosenzweig 1994; Lloyd, Kaufman, and Hewett 2000). Questions of data quality should now take on greater significance given the monitoring requirements built into the UN Millennium Development Goal for education.

As a byproduct of an expanded household questionnaire adopted by the Demographic and Health Survey (DHS) program in the early 1990s, comparable populationbased data on the educational participation and attainment of household members have been collected in many developing countries. ${ }^{3}$ The majority of these DHS surveys have taken place in sub-Saharan Africa, with 26 countries participating since 1990 (see Table 1). ${ }^{4}$ Data from these surveys are highly representative of the total population of subSaharan Africa; indeed, based on United Nations estimates, 83 percent of young people (aged 10-24) living in the region are represented. Sample sizes in the DHS for the 1024 -year age group range from 4,600 to over 22,000 . The median date for these surveys is 1998 and only three of the 26 were fielded prior to $1995 .{ }^{5}$ Because population funding agencies gave less priority to undertaking surveys in low-fertility countries, many Latin American and Asian countries that were further along in their demographic transitions were not included in the DHS program. Hence, the DHS coverage of these regions is less comprehensive.

With so many recent DHS surveys available for sub-Saharan Africa, it is possible to derive estimates of trends in school participation and attainment over the past 30 
Table 1 Sub-Saharan African countries participating in the DHS since 1990

\begin{tabular}{lcc}
\hline Country & $\begin{array}{c}\text { Year of } \\
\text { most recent DHS }\end{array}$ & $\begin{array}{c}\text { Sample size of population } \\
\text { aged 10-24 }\end{array}$ \\
\hline Benin & 1996 & 7,361 \\
Burkina Faso & $1998-99$ & 10,243 \\
Cameroon & 1998 & 8,833 \\
Central African Republic & $1994-95$ & 8,529 \\
Chad & $1996-97$ & 11,149 \\
Comoros & 1996 & 4,852 \\
Côte d'Ivoire & $1998-99$ & 4,654 \\
Ethiopia & 1999 & 22,769 \\
Ghana & $1998-99$ & 6,991 \\
Guinea & 1999 & 10,097 \\
Kenya & 1998 & 13,021 \\
Madagascar & 1997 & 11,080 \\
Malawi & 2000 & 20,884 \\
Mali & 2001 & 19,329 \\
Mozambique & 1997 & 14,730 \\
Namibia & 1992 & 8,714 \\
Niger & 1998 & 11,052 \\
Nigeria & 1999 & 11,589 \\
Rwanda & 2000 & 16,679 \\
Senegal & $1992-93$ & 14,200 \\
South Africa & $1998-00$ & 17,276 \\
Tanzania & 1999 & 6,115 \\
Togo & 1998 & 14,041 \\
Uganda & $2000-01$ & 12,742 \\
Zambia & $1996-97$ & 13,790 \\
Zimbabwe & 1999 & 10,374 \\
\hline Source: & &
\end{tabular}

Source: DHS website.

years. These data tell a story of impressive past progress and daunting current challenges, set in the context of diverse colonial histories, resource endowments, and population growth rates. The data also provide a picture of progress toward the goal of universal primary school completion - a picture that in some ways differs from that portrayed by UNESCO indicators.

The purpose of this paper is threefold: (1) to highlight the value of consistent and comparable population-based data on educational participation and attainment for evaluation, planning, and target setting through comparison of alternative indicators of progress, (2) to extend our knowledge of current patterns and trends in educational achievement among youth in sub-Saharan Africa, and (3) to identify major challenges based on an in- 
depth exploration of schooling differentials by sex and household wealth. Throughout the paper, we present results separately for boys and girls in order to focus on the gender gap in schooling and how it is changing.

\section{INDICATORS OF PROGRESS}

As a follow-up to the Millennium Summit of the United Nations General Assembly in 2000, the Secretary General was asked to provide a road map toward implementation of the UN Millennium Declaration. This road map, adopted a year later by the General Assembly, contained many goals, including ten related to economic development and poverty eradication (United Nations General Assembly 2001). These have entered common parlance as the "Millennium Development Goals." The second of these is worded as follows: "to ensure that, by the year 2015, children everywhere, boys and girls alike, will be able to complete a full course of primary schooling and that girls and boys will have equal access to all levels of education" (United Nations General Assembly 2001). Increasing girls' education is one of the principal strategies identified in the document for achieving universal primary school completion. The wording of the Millennium Development Goal for education is less ambitious than the wording of the Dakar Framework for Action adopted a year earlier, which called for "free and compulsory primary education of good quality" (UNESCO 2002). Currently, only 14 of the 26 sub-Saharan African countries covered in this paper have constitutional guarantees of compulsory schooling and, of these, only nine guarantee free schooling (see Table 2).

Two indicators have been chosen by the international community to monitor progress toward the Millennium Development Goal for schooling. These are the net primary enrollment ratio and the grade four completion rate (UNESCO 2002). The logic behind these two measures is that a level of achievement of 99 percent for both would imply that universal completion of primary school, which can run one to three years beyond grade four, was near at hand.

The net primary enrollment ratio captures, at a particular time, the percent of children of primary school age who are currently enrolled in primary school. ${ }^{6} \mathrm{~A}$ primary net enrollment ratio of 100 would indicate that all children within the eligible ages are enrolled. However, in a context in which many children start school late, it is possible 
Table 2 Key features of educational systems in sub-Saharan Africa: 2000

\begin{tabular}{|c|c|c|c|c|}
\hline & \multicolumn{2}{|c|}{ Constitutional guarantee } & \multirow{2}{*}{$\begin{array}{c}\text { Age of } \\
\text { school entry }\end{array}$} & \multirow{2}{*}{$\begin{array}{c}\text { Years of } \\
\text { primary school }\end{array}$} \\
\hline & Compulsory & Free & & \\
\hline Benin & $\mathrm{x}$ & $\mathrm{a}$ & 6 & 6 \\
\hline Burkina Faso & & & 7 & 6 \\
\hline Cameroon & $\mathrm{x}$ & & 6 & 6 \\
\hline Central African Republic & & & 6 & 6 \\
\hline Chad & $\mathrm{x}$ & $\mathrm{x}$ & 6 & 6 \\
\hline Comoros & $\mathrm{x}$ & & 6 & 6 \\
\hline Côte d'Ivoire & & & 6 & 6 \\
\hline Ethiopia & & & 7 & 4 \\
\hline Ghana & $\mathrm{x}$ & $\mathrm{x}$ & 6 & 6 \\
\hline Guinea & $\mathrm{x}$ & & 7 & 6 \\
\hline Kenya & $\mathrm{x}$ & $\mathrm{x}$ & 6 & 7 \\
\hline Madagascar & $\mathrm{x}$ & $\mathrm{x}$ & 6 & 5 \\
\hline Malawi & $\mathrm{x}$ & $\mathrm{x}$ & 6 & 4 \\
\hline Mali & $\mathrm{x}$ & $\mathrm{x}$ & 7 & 6 \\
\hline Mozambique & & & 6 & 5 \\
\hline Namibia & $\mathrm{x}$ & & 6 & 7 \\
\hline Niger & & & 7 & 6 \\
\hline Nigeria & $\mathrm{x}$ & $\mathrm{x}$ & 6 & 6 \\
\hline Rwanda & $\mathrm{x}$ & $\mathrm{x}$ & 7 & 6 \\
\hline Senegal & & & 7 & 6 \\
\hline South Africa & $\mathrm{x}$ & $\mathrm{x}$ & 7 & 7 \\
\hline Tanzania & & & 7 & 7 \\
\hline Togo & $\mathrm{a}$ & $\mathrm{a}$ & 6 & 6 \\
\hline Uganda & $\mathrm{a}$ & $\mathrm{a}$ & 6 & 7 \\
\hline Zambia & & & 7 & 7 \\
\hline Zimbabwe & $\mathrm{a}$ & $\mathrm{a}$ & 6 & 7 \\
\hline
\end{tabular}

a: "To be progressively introduced."

Sources: UNESCO (2002) and Tomasevski (2001).

for a country to have achieved the goal of primary completion while having a ratio below 100. This could occur if everyone in a particular cohort completed primary school, but some began after the normal starting age and therefore completed school beyond the recommended age.

Furthermore, net primary enrollment ratios are not strictly comparable across countries because of variations in the length of the primary school cycle. From Table 2 we can see that, in our sample of 26 countries, two have a primary school cycle of four years, two have five years, 15 have six years, and seven have a cycle of seven years. ${ }^{7}$ Countries are 
free to design their own school systems, and international standards have not been established for the length of a primary school cycle. Using the millennium goal for primary schooling, countries with a longer primary cycle are currently judged by a tougher standard than countries with a shorter cycle. This is because the denominator of the ratio is customized to the number of years in the primary cycle in each country. The ratio is also set according to the recommended starting ages in each country, even if enrollment and attendance ages are poorly promoted or enforced. Sixteen of the 26 countries have recommended starting ages of six, while the other ten have recommended starting ages of seven. Countries with earlier recommended starting ages may have more difficulty achieving a higher net primary enrollment ratio than countries with later recommended starting ages.

The UNESCO net primary enrollment ratio is based on first-day enrollments as officially reported by schools throughout the country to the national ministry of education. These enrollment numbers are divided by United Nations estimates of the population for the year and ages in question. The quality of these enrollment estimates is directly tied to the quality of the underlying management information systems on which they are based. The development of good management information systems is a continuing challenge in many parts of Africa (Moulton et al. 2001). Where financial flows to schools are related to the level of enrollment, there is substantial motivation on the part of local education offices to inflate these numbers. Although changes in systems of reporting that make current data more accurate are welcome, they may nonetheless compromise comparability over time.

Data from the DHS household survey can be used to derive alternative estimates of primary school participation applicable to the year of the survey. In each of these nationally representative surveys, data on educational participation and attainment were collected for every member of the household. Information on current school status was obtained for those between ages 5 and 24. Because a survey can extend over several months, the DHS has the disadvantage of capturing households at different stages of the annual school cycle. While the wording of the DHS question is intended to capture all who are still enrolled in school, even if they are not currently attending because of illness, school vacation, or other circumstances, some researchers suggest that the DHS measures of school participation should be termed measures of attendance rather than measures of enrollment. ${ }^{8}$ 
The net primary attendance ratio derived from the DHS data is likely to provide a more realistic picture of school participation than the net primary enrollment ratio derived from the UNESCO data, given that the former includes only those who have actually attended school and is based on a numerator and denominator that are derived from the same population base. The DHS estimate also has the advantage that it can be presented for separate subpopulations, including those grouped by household wealth status. While UNESCO provides annual data on trends in the net primary enrollment ratio for those countries reporting enrollment data by age, such data are not available for all countries. In the case of sub-Saharan Africa, only 18 of the 26 DHS-surveyed countries have enrollment data from UNESCO that match within one to two years of the dates of the DHS survey.

Table 3 compares estimates of the net primary enrollment ratio for boys and girls from UNESCO and of the net primary attendance ratio from DHS, using the same age ranges for each country and closely matching dates. ${ }^{9}$ Figure 1 combines these two estimates for each country, separately for boys and girls, in scatter plots that relate the pairing of estimates to a 45-degree line representing complete consistency between the two estimates. While a majority of points lie reasonably close to the diagonal, there is a tendency for the UNESCO estimates to be higher than those of the DHS. ${ }^{10}$ This is highlighted in Figure 1 by the larger number of cases falling, sometimes significantly, below the diagonal. These comparisons reinforce suspicions about the inflation of ministry reporting of enrollment in some countries (Lloyd, Kaufman, and Hewett 2000) and the likelihood that many children are enrolled in, but never actually attend, school (UNESCO 2002).

Table 3 also compares two estimates of the gender gap in primary school participation. The gender gap in enrollment implied by UNESCO estimates is systematically higher than the gender gap in attendance implied by DHS. These findings suggest a differential inflation of school participation by sex in the UNESCO estimates, with either structural elements built into some management information systems that lead to this type of inflation for boys or the fact that boys are more likely than girls to be enrolled in, yet never attend, school. While norms about the importance of enrolling boys are likely to be pervasive, norms about girls' enrollment are probably less strongly held. As a result, the registration of girls on the first day of school may reflect a strong com- 


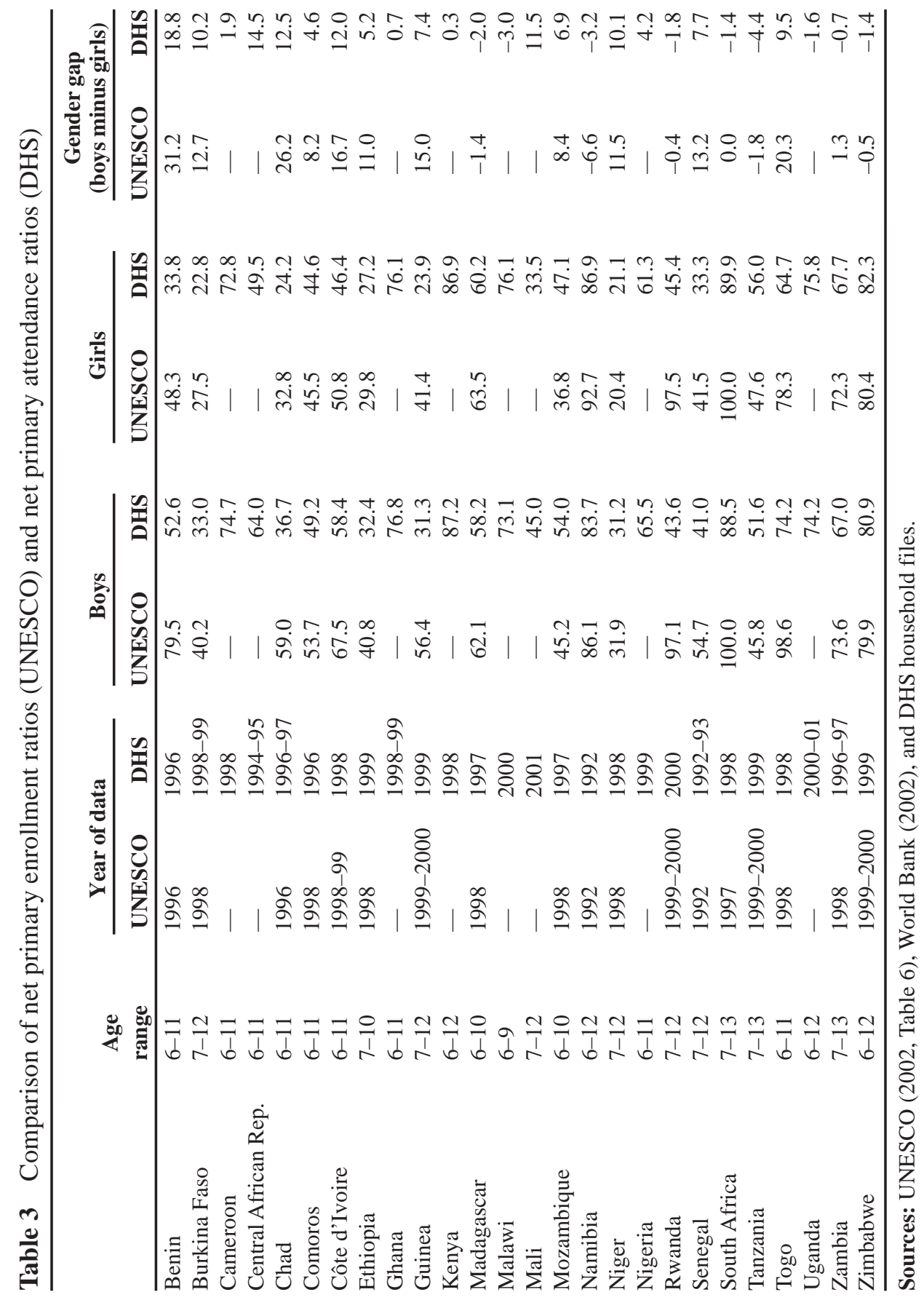


Figure 1 Comparison of net primary enrollment and attendance ratios: UNESCO vs. DHS
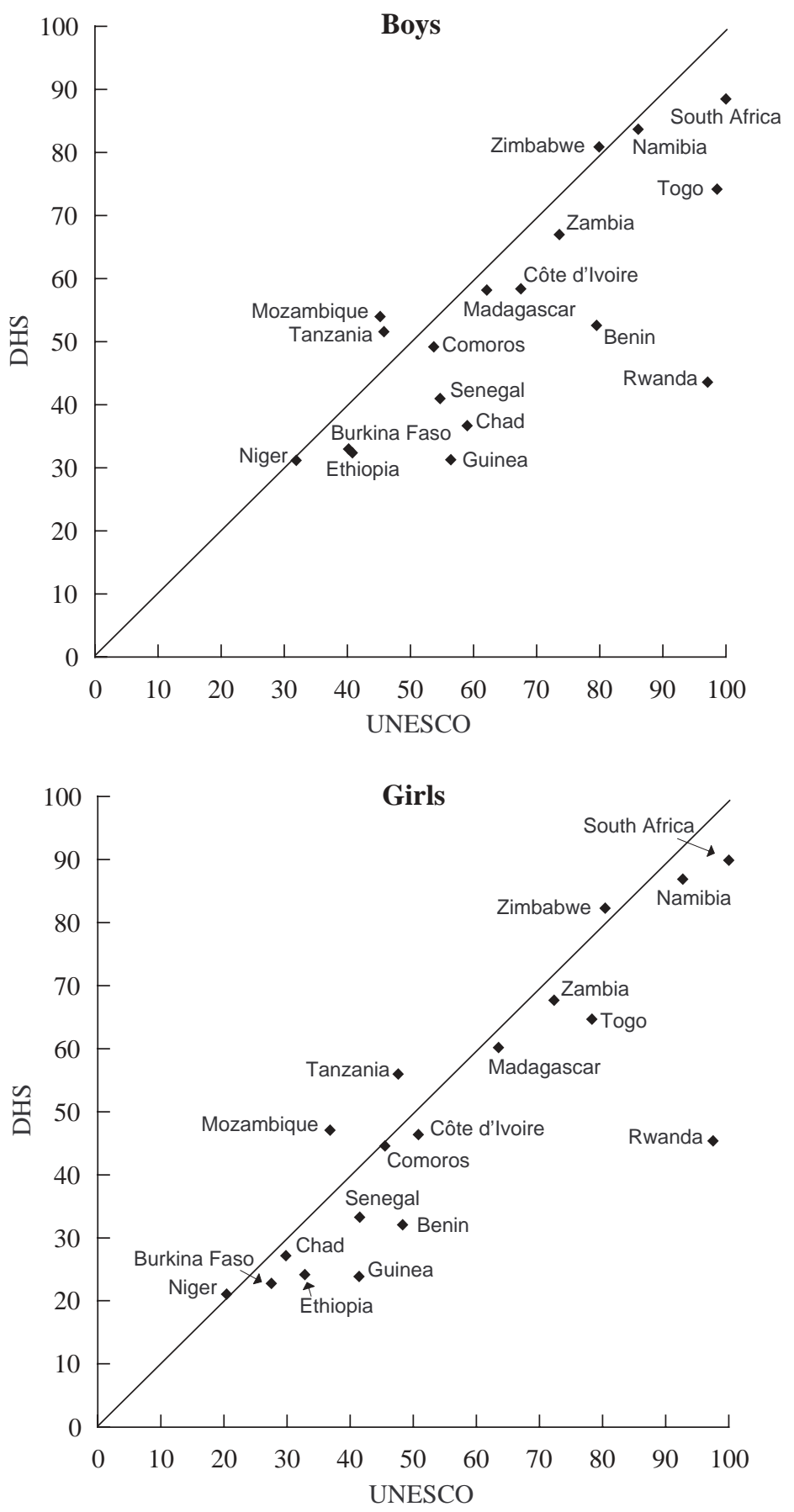

Source: Table 3 . 
mitment by parents to their daughters' regular attendance, whereas first-day enrollments for boys are likely more routine and less indicative of parental commitment. Regardless of how these discrepancies are interpreted, UNESCO enrollment estimates imply much larger gender gaps in school participation than do DHS attendance estimates.

We can also compare UNESCO and DHS data with regard to grade four completion, the second indicator adopted for monitoring progress toward the millennium education goal. The UNESCO estimate for grade four completion, also called the survival rate at grade five, is a ratio of the number of children officially enrolled in grade five in a given year relative to the number of children who officially enrolled in grade one four years earlier. ${ }^{11}$ This may or may not capture the actual percent of any particular schoolentering cohort that completes grade four, because it does not account for any repetition or temporary withdrawal. It is also not restricted to children of a common age. In countries with high repetition or withdrawal, this statistic would underestimate the percent of children who eventually complete grade four. An alternative measure that can be derived from the DHS, and that does not have these limitations, is the percent of 15-19year-olds who have completed four or more years, among those who have ever entered school. This measure accommodates late starters and allows comparisons across age cohorts. It is, however, less contemporaneous than the UNICEF indicator. ${ }^{12}$

Table 4 compares alternative estimates of grade four completion derived from UNESCO and from DHS. Data for this indicator are available from UNESCO for 18 of the 26 countries. Figure 2 presents scatter plots of points derived from the data in Table 4. With one or two exceptions, DHS estimates are higher than UNESCO's for both boys and girls. We suspect this is because the DHS measure is not time bound and includes students who take more than four years to complete grade four. Where comparisons are possible, half the countries show gender gaps that are roughly consistent in magnitude while half show gender gaps that are inconsistent in magnitude, and sometimes even of inconsistent signs. These inconsistencies cannot be readily explained, thus raising questions about the cross-country comparability of these estimates.

From these comparisons, we conclude that UNESCO provides an incomplete and sometimes potentially biased picture of progress toward the millennium education goal with the current data derived from country management information systems. Com- 


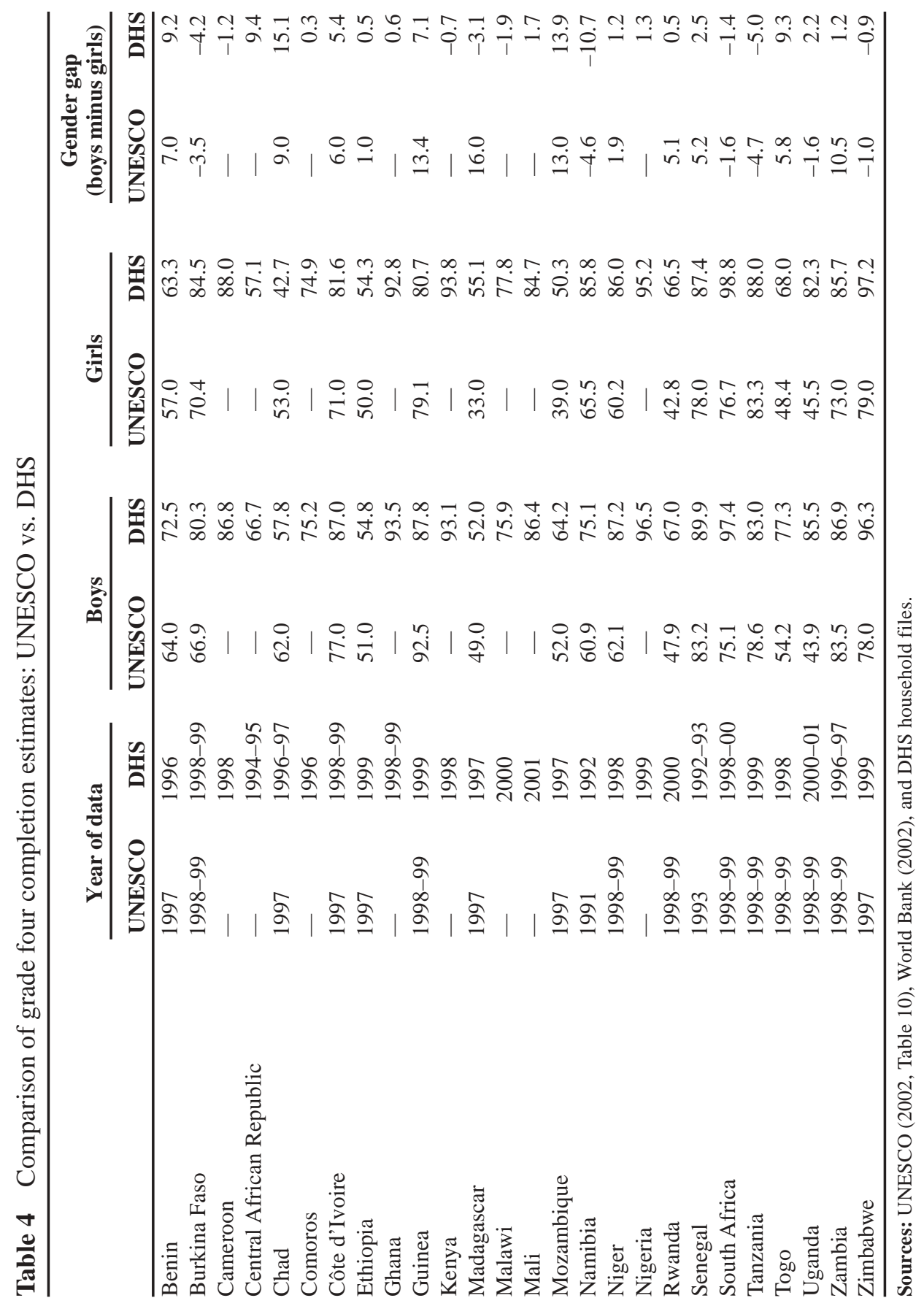


Figure 2 Comparison of alternative estimates of grade four completion rates: UNESCO vs. DHS
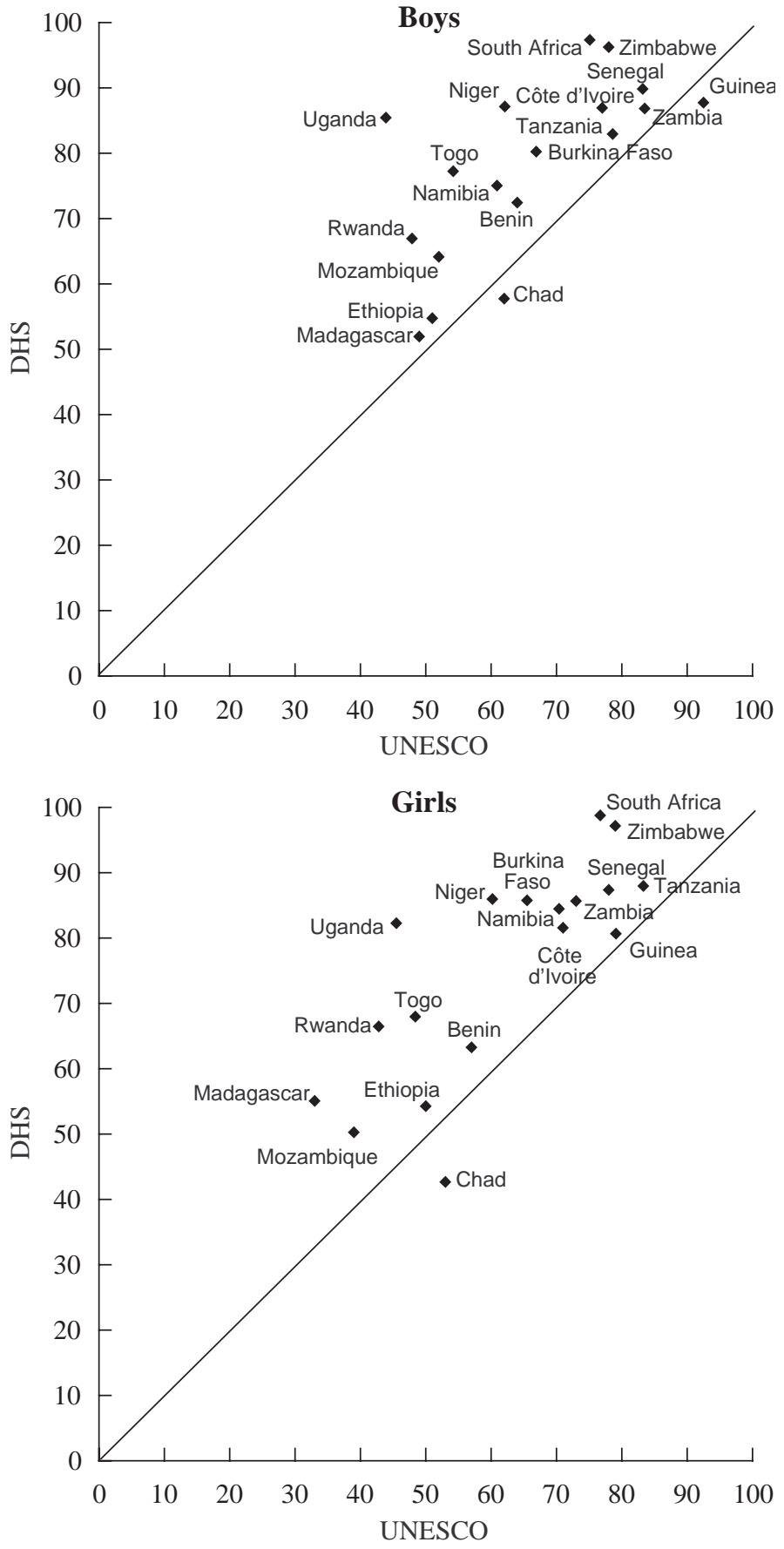

Source: Table 4. 
parisons with data from the DHS suggest that fewer children ever attend school than the UNESCO estimates suggest, but a higher percentage of those who do attend eventually complete grade four. Furthermore, gender gaps in school participation are likely to be smaller than implied by UNESCO enrollment estimates. In the next section of the paper, we rely entirely on DHS data to derive country-specific as well as region-wide trends. In our view, these data provide an alternative and potentially more accurate portrayal of past educational achievement and current challenges than trends derived from the UNESCO data previously discussed.

\section{Trends in EduCATIONAL PARTicipation}

\section{AND A TTAINMENT}

Trends in schooling can be derived using the most recent DHS survey for each country by comparing cohort differences in educational participation and attainment. We look primarily at two indicators of progress: (1) the percent completing four or more grades and (2) the percent completing primary school. Unlike the indicator of grade four completion reviewed in the previous section, which is restricted to those who ever attended, the DHS measure used here is calculated to include all individuals within each age group.

To ensure comparability across cohorts, the youngest five-year age cohort chosen for each indicator has to have reached a sufficient age to be assured of achieving the level of schooling captured by that indicator. ${ }^{13}$ In the case of the percent completing four or more grades, a minimum age of 15 is required for this measure in light of late starting ages (Table 2); not all children can safely be assumed to complete grade four until age 15 in many sub-Saharan African countries. For the second indicator-completed primary school - the base cohort is 20-24-year-olds because, in countries with longer primary cycles, students may still be enrolled in primary school at age 18 (Lloyd, Mensch, and Clark 2000).

Several advantages are associated with deriving trends from a single survey. First, one can compare more countries, as only 15 of the 26 countries have had more than one DHS survey since 1990, the year when DHS added education to the household questionnaire. Second, the mean interval between surveys is no more than six years, and one can explore trends over a longer interval of time using a single survey. Third, there is inter- 
nal comparability within one sample survey that cannot necessarily be assumed when comparing more than one survey. ${ }^{14}$

On the other hand, there is some loss in comparability when deriving long-term trends from one survey, owing to differential mortality by educational attainment. Some of those educated in the past will not be alive at the time of the survey and, therefore, their educational attainment will not be reported. Mortality will be selective of the least educated and will therefore lead to an overestimate of educational attainment in earlier time periods, thus biasing down estimated rates of progress. Indicators for the current period are not affected by differential mortality. Because mortality rates are relatively low for individuals in their 20s and 30s, this is likely to be a minor source of bias for trend estimates over the last two decades.

Table 5 presents trends in indicators of educational participation and attainment for sub-Saharan Africa as a whole, separately for males and females. For comparability, data are shown for the percent who have ever attended school, including estimates for the youngest age cohort, those aged 10-14, as well as for the two indicators of educational attainment. The trends in Table 5 are based on weighted averages, using the population aged 10-24 in 2000 (as estimated by the United Nations) as the weight for each country. ${ }^{15}$ Given that the trends for all three indicators track very closely together over the age cohorts, it is possible to bring the estimates of grade four completion and primary school completion up-to-date by estimating grade four completion rates for 10-14-year-olds and completed primary school rates for those aged $15-19$ and $10-14 .{ }^{16}$ As a result we can present trends in both indicators of educational attainment up through the late 1990s. These are illustrated in Figure 3.

For boys, the percent completing primary school is estimated to have risen in sub-Saharan Africa from roughly 46 percent in the late 1960s to roughly 57 percent in the late 1990s. However, the primary school completion rates have stayed the same since the early 1980s. Indeed, most of the improvement in primary completion came in the 1960s and 1970s. In fact, boys in sub-Saharan Africa have recorded little progress in the percent completing primary school in the last 30 years.

In stark contrast, over the same time period girls' primary school completion rates have risen steadily from a much lower base of around 26 percent to 53 percent, 
Table 5 Trends in educational participation and attainment (percent) weighted by population, 26 African countries

\begin{tabular}{|c|c|c|c|c|c|c|c|c|c|}
\hline \multirow[b]{2}{*}{ Age group } & \multicolumn{3}{|c|}{ Ever attended school } & \multicolumn{3}{|c|}{ Completed $4+$ years } & \multicolumn{3}{|c|}{ Completed primary } \\
\hline & Males & Females & $\begin{array}{c}\text { Gender } \\
\text { gap }^{\mathrm{a}}\end{array}$ & Males & Females & $\begin{array}{c}\text { Gender } \\
\text { gap }^{\mathrm{a}}\end{array}$ & Males & Females & $\begin{array}{c}\text { Gender } \\
\text { gap }^{\mathrm{a}}\end{array}$ \\
\hline $10-14$ & 77.8 & 72.2 & 5.6 & $68.2^{*}$ & $63.3^{*}$ & $4.9^{*}$ & $57.2^{*}$ & $52.9^{*}$ & $4.3^{*}$ \\
\hline $15-19$ & 80.4 & 70.8 & 9.5 & 68.3 & 60.4 & 7.9 & $57.3 *$ & $50.1 *$ & $7.2 *$ \\
\hline $20-24$ & 78.2 & 66.1 & 12.1 & 68.9 & 57.9 & 10.9 & 57.3 & 47.2 & 10.1 \\
\hline $25-29$ & 76.3 & 63.4 & 13.0 & 68.1 & 55.1 & 13.0 & 56.9 & 44.4 & 12.5 \\
\hline $30-34$ & 73.7 & 58.0 & 15.7 & 65.6 & 49.4 & 16.2 & 55.5 & 39.3 & 16.1 \\
\hline $35-39$ & 71.9 & 51.1 & 20.8 & 63.8 & 42.6 & 21.2 & 53.5 & 32.9 & 20.6 \\
\hline $40-44$ & 65.2 & 44.0 & 21.2 & 56.3 & 34.9 & 21.4 & 45.8 & 25.9 & 19.9 \\
\hline $\begin{array}{l}\text { Change for mos } \\
\text { recent decade }\end{array}$ & -0.5 & 9.3 & -54.0 & -0.1 & 9.3 & -55.0 & 0.0 & 12.1 & -57.4 \\
\hline $\begin{array}{l}\text { Change for } \\
\text { earlier decade }\end{array}$ & 6.1 & 14.0 & -23.1 & 5.0 & 17.2 & -32.7 & 3.2 & 20.1 & -37.3 \\
\hline $\begin{array}{l}\text { Change } \\
\text { over } 20 \text { years }\end{array}$ & 5.5 & 24.6 & -64.6 & 4.0 & 28.1 & -69.8 & 3.1 & 34.6 & -73.3 \\
\hline
\end{tabular}

${ }^{\mathrm{a}}$ Males minus females.

*Estimates prepared by authors.

Note: Weighting based on 2000 UN estimates for population 10-24.

Source: DHS data files

roughly doubling the level of achievement since the 1960s. The pace of progress for girls, which was very rapid earlier on, has slowed in the last 20 years. For girls, these trends reflect not only an increase in attendance, but also a small improvement in retention rates. With these different trajectories, the gender gap, which was very wide in the early days of independence, has narrowed considerably: current estimates for sub-Saharan Africa as a whole put the gap at only 4 percentage points in favor of boys.

Grade four completion rates are slightly higher than primary completion rates for both boys and girls, implying an attrition rate between the end of grade four and primary completion of roughly 10 percentage points. In the current period, an estimated 63 percent of girls and 68 percent of boys aged 10-14 have completed at least four grades. Two worrying developments for boys are the stagnation in grade four completion for the last 15 to 20 years at around 68 percent and the small recent decline from 69 to 68 percent. While 80 percent of 15-19-year-old boys had ever been to school, the percent has fallen to 78 percent for the 10-14-year-olds (see Table 5). This suggests the possibility of a future erosion in boys' schooling attainment for the next decade. Given that 
Figure 3 Trends in educational attainment: 26 African countries
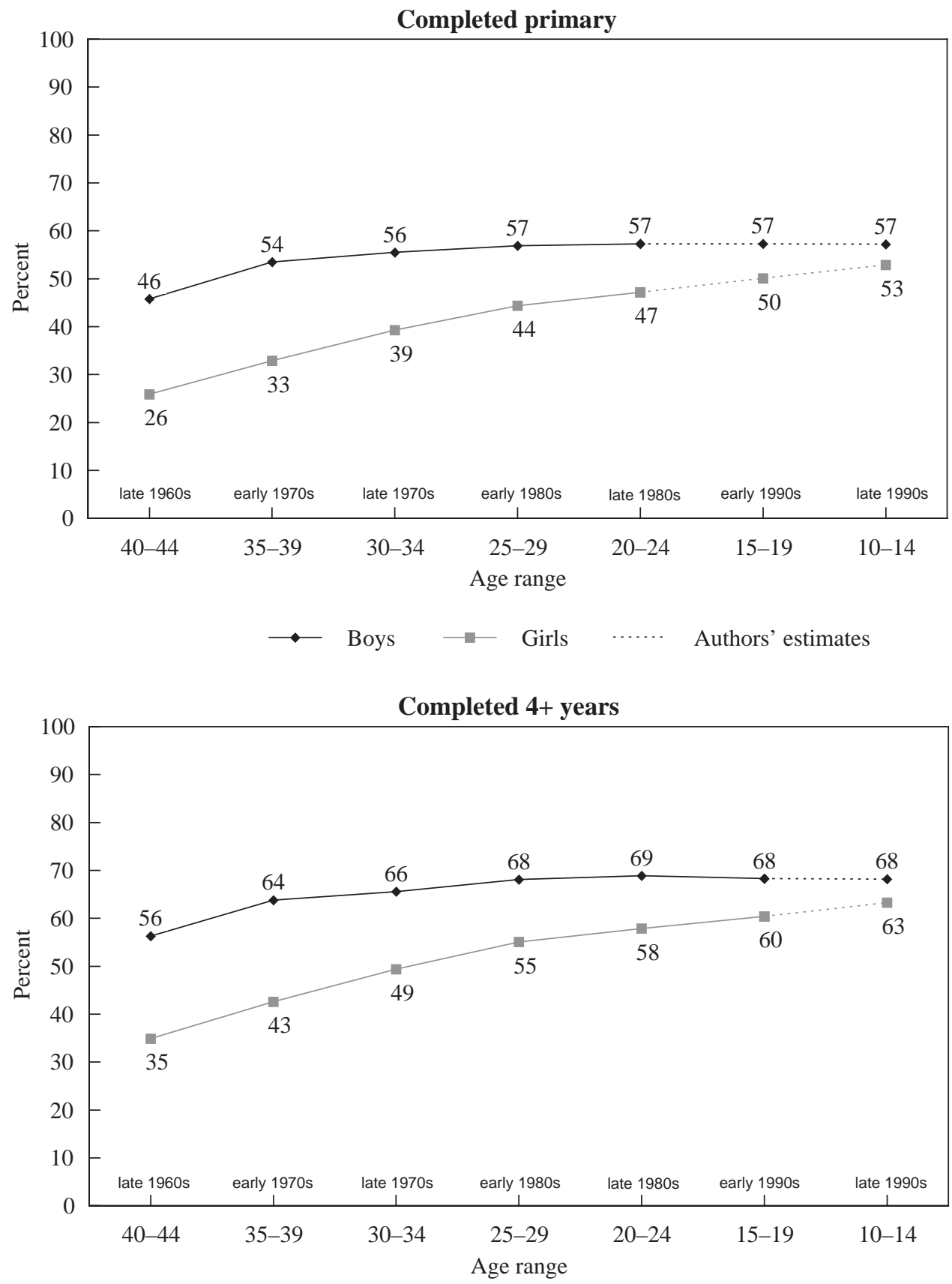

$\longrightarrow$ Boys $\quad$ Girls $\quad \cdots . .$. Authors' estimates

Source: DHS data. 
these weighted regional averages hide the current achievement of a large number of poorly performing countries, many countries will witness even greater declines in education among boys.

As with primary school completion rates, grade four completion rates for girls have increased markedly over time, although clearly a large part of the growth was for older age cohorts. As a result, the estimated gender gap for grade four completion has declined to 5 percentage points for the late 1990s. With the decline in boys' attendance coupled with increases in girls' attendance and grade four completion, girls are likely to meet or surpass boys on this indicator in the near future. However, although attendance and grade four completion for girls continue to increase, the pace of these trends is much slower than in the past. It is possible that the trends in girls' schooling will eventually parallel the flatter trends for boys that have occurred in the last three decades or so.

These long-term trends mirror economic and political developments for the region as a whole. In the early postcolonial period, the importance accorded to schooling in national development plans led to a dramatic increase in educational expenditure and a tremendous expansion of educational infrastructure, irrespective of differing development strategies. ${ }^{17}$ These investments were facilitated by strong economic growth rates in the late 1960s and the 1970s (Kinyanjui 1993; World Bank 1988). Total public expenditure on education in constant dollars grew on average by roughly 7 percent a year between 1970 and 1980 across sub-Saharan Africa, with similar rates of growth recorded in the former British and French colonies. These average rates of growth were well above those required to keep pace with the growth in school-age populations (Donors to African Education 1994). Indeed, growth of educational expenditure exceeded growth in gross national product (GNP) in the 1970s, resulting in a rising fraction of GNP devoted to educational expenditure.

The economic, political, and demographic conditions in the 1980s, however, sharply curtailed and often ended the impressive educational gains of the previous two decades. Population continued to grow rapidly, with rates of growth in most countries even higher in the 1980s than in the 1970s (United Nations 2001). African countries were particularly hard hit by increased world prices for oil, decreased export prices, and 
higher external debt (Hodd 1989; World Bank 1988). Additionally, most countries adopted structural adjustment programs that resulted in cutbacks in social-sector spending, including educational expenditures, often leading to the imposition of school fees (Reimers 1994). ${ }^{18}$ This retraction of national investment in education is reflected in declines in the growth rate of educational expenditures in constant dollars from 6.2 percent on average for $1970-80$ to 2.1 percent for 1980-90 (Donors to African Education 1994).

In addition to economic decline in the region, for many other countries in Africa during the 1970s and 1980s (for example, Angola, Ethiopia, Liberia, Mozambique, Nigeria, Sierra Leone, Somalia, and Sudan) political instability and internal conflict resulted in marked declines in education and its infrastructure, including a reduction in the depth and breadth of educational development (Kinyanjui 1993). For example, nine years after the Amin coup in 1971, Uganda had the lowest per-pupil spending levels among all sub-Saharan countries, and this pattern continued until 1990 (Donors to African Education 1994). In Nigeria, political instability led to a continuous decline in educational expenditures averaging 15.7 percent per year during the 1980s (ibid.). The impact of instability and conflict on education was no less relevant in the 1990s for countries such as Burundi, Congo, Ethiopia, Rwanda, and most recently Côte d'Ivoire. The good news is that, as Mozambique and Uganda have emerged in the 1990s from their tragic earlier history, they have shown impressive recent gains in educational indicators.

Because some of the most populous countries in Africa, measured in terms of the size of their adolescent population in 2000, have achieved higher levels of schooling than their smaller neighbors, weighted averages give a more optimistic picture of the trends in schooling than would be the case if each country were given the same weight in the analysis. ${ }^{19}$ The most populous countries that have participated in the DHS survey program with relatively strong educational performance include Nigeria with 37.6 million 10-24-year-olds, South Africa with 13.7 million, Tanzania with 11.8, Kenya with 11.3, Uganda with 7.8, and Ghana with 6.6. Of the more populous countries, only Ethiopia, with 20 million 10-24-year-olds, has had relatively poor educational performance. Thus, more than half the countries represented in this analysis face even greater challenges in achieving "Education for All" than would be implied by these data. 
The range of experience across countries in grade four completion and primary school completion, and patterns of recent changes, are depicted in Figure 4, using a scatter plot to array each indicator for boys and girls separately at two points in time. Points to the left of the diagonal line indicate a growth in attendance in the recent decade and points to the right of the line indicate recent declines. For the percent completing grade four, shown in the top panel of Figure 4, half of the countries in our sample have recent grade four completion rates for girls below 50 percent while, in the case of boys, this is true for roughly a third of our sample countries. On the other hand, in the past ten years girls are more likely to have shown improvements in grade four attainment relative to boys. From the bottom panel of Figure 4, we can see that no country has achieved universal primary school completion. Indeed, primary completion rates for most countries fall below 50 percent. Again girls are more likely to have experienced recent improvements than boys.

Appendix Tables 1 and 2 present data on the performance of individual countries for each indicator. Looking at the range of experience across the 26 countries, we see tremendous variation in performance over time, by sex, by decade, and by indicator. Again, the majority of countries fall below the levels of schooling implied by the weighted averages presented in Table 5 .

Starting with trends in grade four completion rates in Appendix Table 1, we see that over a 20-year period (comparing the cohort aged 15-19 with the cohort aged 35-39), three countries have seen sharp declines in grade four completion for boys: Madagascar, Tanzania, and Zambia. In the more recent past, many more countries have experienced setbacks in grade four completion for boys, including Cameroon, Central African Republic, Côte d'Ivoire, Ethiopia, Kenya, Namibia, Rwanda, and Zimbabwe. Girls have also experienced setbacks in grade four completion rates in the last decade in Côte d'Ivoire, Madagascar, Rwanda, and Tanzania. Mali and Mozambique, which had experienced declines for boys in the earlier decade, recorded impressive growth in the recent decade, more than erasing earlier losses. Again, in all 26 countries, the gender gap in grade four completion has narrowed, with the most dramatic percentage changes in French West Africa where the largest absolute gaps still remain. For example, in Benin, Central African Republic, Guinea, Mozambique, and Togo the gender gap still exceeds 20 percentage points. 
Figure 4 Trends in educational attainment: 26 African countries

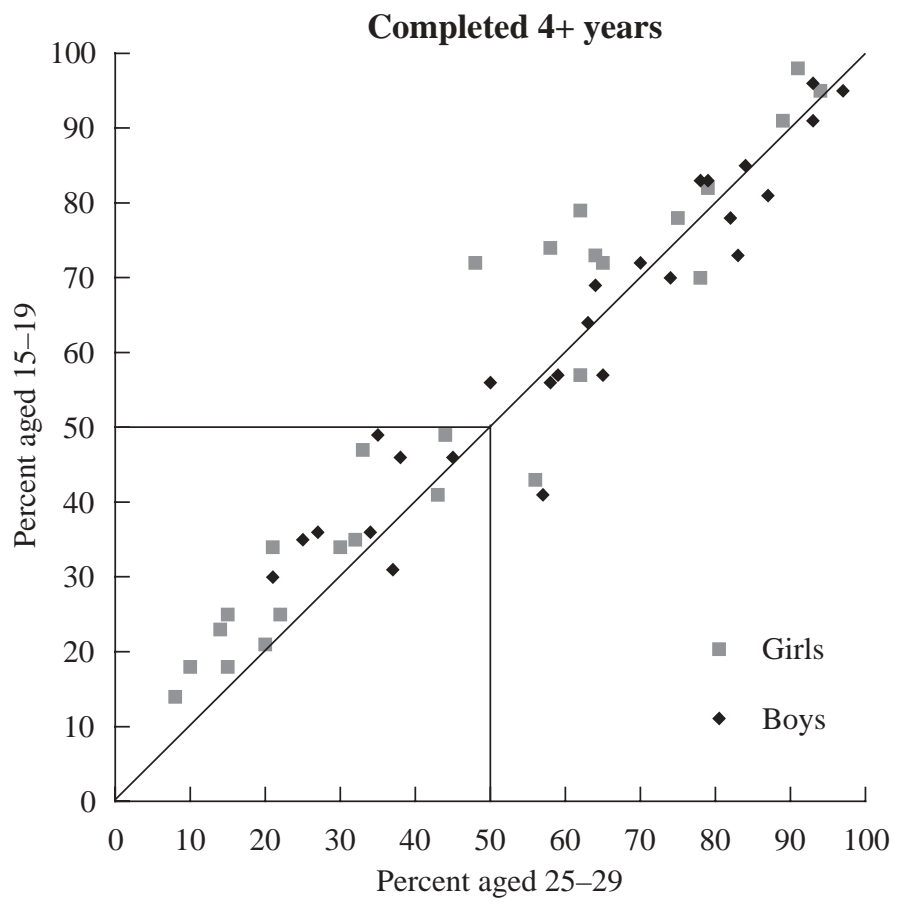

Source: Appendix Table 1.

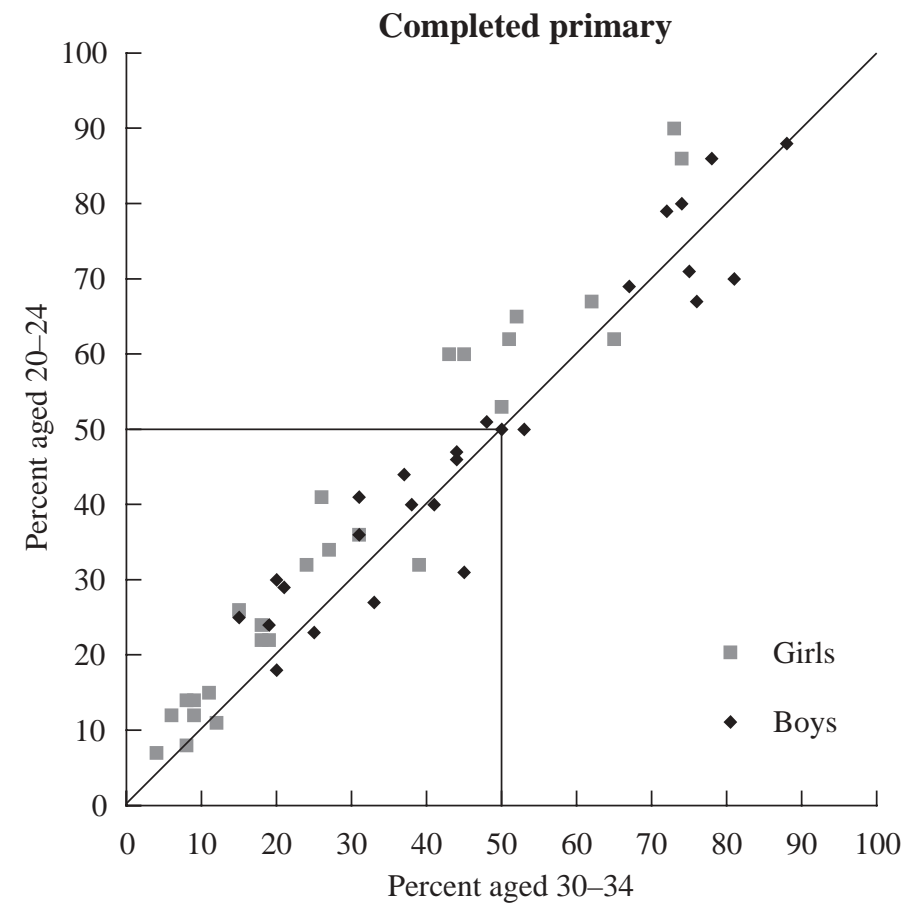

Source: Appendix Table 2 . 
In the most recent decade for which comparisons are possible (cohort aged 20-24 compared with the cohort aged 30-34), ten countries have seen declines in primary completion rates for boys (Appendix Table 2). These are Benin, Ethiopia, Kenya, Madagascar, Mozambique, Namibia, Rwanda, Tanzania, Togo, and Zambia. Three of these have also seen declines for girls: Benin, Kenya, and Madagascar. During this same decade, most of the same countries saw increases in attendance rates, suggesting the difficulties not only of entering school but also of staying in school until the end of the primary cycle. These declines in attendance and retention in different countries at different points in time remind us that, in the context of economic, political, and bureaucratic uncertainty, steady progress cannot be taken for granted.

\section{Current Challenges}

In the 1990s, qualitative evaluations of the educational situation in sub-Saharan Africa described a thinning of the provision of education and the inability of countries to maintain current levels of educational achievement given lagging growth in investment and continuing growth in the size of school-age cohorts (Kinyanjui 1993; Nieuwenhuis 1996). While UNESCO provides recent estimates of total public expenditure on education as a percent of GNP for 17 of the 26 countries in our sample (UNESCO 2002), it is difficult to link these estimates with data from earlier time periods because of noncomparability in the accounting of expenditure. ${ }^{20}$

In response to these negative trends and in light of the goal of Education for All set in Jomtien in 1990, many African countries adopted educational reform measures in the 1990s, usually in collaboration with international donors, to improve efficiency, mobilize resources, and reallocate expenditures away from tertiary and toward more basic levels of schooling (Samoff and Sumra 1994). Two key elements of school reform in many contexts have been policies to decentralize governance structures (including devolution of responsibility for educational delivery to lower levels of government, parentteacher associations, and the involvement of the private sector) and policies to achieve greater financial accountability (such as the imposition of user fees). A recent analysis by Colclough and Al-Samarrai (2000) suggests that Education for All is achievable within current budget constraints if governments give greater budgetary priority to the primary 
sector and reduce unit costs of schooling by improving efficiency and controlling teacher salaries in countries where they are relatively high.

Current educational reform efforts are faring very differently in different contexts. A review of recent reform efforts in Benin, Ethiopia, Guinea, Malawi, and Uganda suggests that the process has been more complicated and expensive than originally anticipated (Moulton et al. 2001). In each of these five cases, external donor funds from USAID and the World Bank represent a substantial share of current public expenditures on education, ranging from 14-15 percent in Ethiopia and Uganda to as high as 43 percent in Guinea. ${ }^{21}$ Not one of these countries has been able to implement more than some aspects of the very elaborate plans that have been adopted. While all ministries reallocated more funds to primary education, Benin, Guinea, and Malawi were not able to allocate those monies effectively so as to benefit individual schools. Ministries are still struggling to create effective management information systems. Some attempt has been made to train more teachers and the production and delivery of educational materials has improved, but the process of revising the curriculum has just begun.

While we are unaware of internationally comparable data on levels and trends in the distribution of school costs between various levels of government and parents themselves, many country case studies document increases in school fees and complementary out-of-pocket costs, such as for textbooks and uniforms (Mehrotra and Delamonica 1998; Grootaert 1994; Bradshaw and Fuller 1996). This widespread rise in the share of total schooling costs paid by parents has taken different forms depending on the context (Knowles and Behrman 2003). However, in a few countries that have returned to multiparty rule with democratic elections, school fees have been abolished in response to pressure from the electorate-for example, in Malawi and Uganda (Moulton et al. 2001) and, most recently, Kenya (Lacey 2003). These decisions, driven by political considerations, have led to strains in the system as enrollments shot up overnight without corresponding changes in facilities and staffing. Clearly, given popular aspirations and international insistence, African governments are under increasing pressure to achieve universal primary schooling. At the same time, financial constraints are making it exceedingly difficult to raise enrollment rates without jeopardizing educational quality and, by extension, retention rates in the longer term. 
While UNESCO data do not allow us to explore differential attainment of Education for All goals by household wealth status, this is possible with DHS data. This fact provides a particular advantage to the DHS data for monitoring educational levels and attainment, given that many current reform efforts are attempting to target resources where they are most needed. Using the household wealth index created by Filmer and Pritchett (1999), we developed an index of educational inequality by household wealth. The inequality index is calculated as one minus the ratio of the grade four attainment of the poorest 40 percent of households, relative to the wealthiest 20 percent of households. This measure of educational inequality ranges from 0 to 1 , with 0 representing complete parity of attainment between the richest 20 percent and the poorest 40 percent in a given country and a value of 1 indicating a complete lack of educational opportunities for the poor. A measure of 0.5 implies that the poor have reached 50 percent of the levels of attainment of the rich. Because household wealth status is measured at the time of the survey, not at the time when schooling decisions are made, we present results for grade four completion rather than primary completion because the former are available for a younger age group.

Table 6 presents the inequality index for grade four completion by wealth status for boys and girls separately as well as the gender gap. The 26 countries are ordered from high to low inequality using the index for boys as the baseline. The first 11 countries listed have indexes for both boys and girls that exceed .50, suggesting wide differentials in educational attainment by household wealth status in sub-Saharan Africa. In most of these countries, the inequality index takes on extreme values ranging between .70 and .90 , indicating almost a complete lack of educational opportunities for the poorest segment of the population. A few additional countries have levels of inequality that exceed .50 only for girls, namely Côte d'Ivoire, Togo, and Comoros. On the other hand, the last three countries listed in the table have achieved universal schooling even for the poor. Relatively low indexes around 20 can be seen for both sexes in Rwanda and Ghana, for boys in Tanzania, and for girls in Namibia.

In many countries, the index of inequality is substantially higher for girls than boys, supporting the widely held belief that gender inequalities in educational attainment are magnified among the poor. Differences of 10 percentage points or more in the index between boys and girls can be found in 14 of the 26 countries. Such gender differences tend to be greatest in countries where overall wealth inequalities are greatest. It is 
Table 6 Index of inequality in grade four completion for 15-19-year-olds, by household wealth

\begin{tabular}{|c|c|c|c|}
\hline Country & Boys & Girls & $\begin{array}{c}\text { Gender gap } \\
\text { (boys minus girls) }\end{array}$ \\
\hline Mali & 0.87 & 0.91 & -0.04 \\
\hline Burkina Faso & 0.83 & 0.90 & -0.07 \\
\hline Madagascar & 0.77 & 0.74 & 0.03 \\
\hline Ethiopia & 0.76 & 0.90 & -0.14 \\
\hline Benin & 0.74 & 0.93 & -0.19 \\
\hline Senegal & 0.73 & 0.84 & -0.11 \\
\hline Guinea & 0.71 & 0.93 & -0.22 \\
\hline Chad & 0.70 & 0.91 & -0.21 \\
\hline Niger & 0.69 & 0.91 & -0.22 \\
\hline Mozambique & 0.64 & 0.83 & -0.19 \\
\hline Central African Republic & 0.56 & 0.84 & -0.28 \\
\hline Côte d'Ivoire & 0.48 & 0.67 & -0.19 \\
\hline Cameroon & 0.38 & 0.46 & -0.08 \\
\hline Namibia & 0.38 & 0.22 & 0.16 \\
\hline Togo & 0.37 & 0.57 & -0.20 \\
\hline Zambia & 0.35 & 0.32 & 0.03 \\
\hline Nigeria & 0.34 & 0.48 & -0.14 \\
\hline Comoros & 0.32 & 0.66 & -0.34 \\
\hline Uganda & 0.29 & 0.45 & -0.16 \\
\hline Malawi & 0.28 & 0.28 & - \\
\hline Rwanda & 0.24 & 0.22 & 0.02 \\
\hline Ghana & 0.21 & 0.19 & 0.02 \\
\hline Tanzania & 0.21 & 0.35 & -0.14 \\
\hline South Africa & 0.06 & 0.04 & 0.02 \\
\hline Zimbabwe & 0.04 & 0.06 & -0.02 \\
\hline Kenya & 0.03 & 0.04 & -0.01 \\
\hline
\end{tabular}

Note: Countries are listed in descending order by index value for boys. For a description of the index see text. Source: DHS data.

interesting to note, however, that this pattern is not universal. Indeed in a substantial minority of countries, representing the full range in terms of schooling inequalities by household wealth status, we find similar levels of inequality for boys and girls. And in several countries inequalities for boys are greater than those for girls: Madagascar, Namibia, Zambia, Rwanda, Ghana, and South Africa.

Figure 5 contrasts the levels of grade four completion currently achieved by $15-$ 19 -year-olds from the poorest 40 percent and the wealthiest 20 percent of households. Countries are ordered from low to high according to the grade attainment of boys in the poorest households. Nearly universal grade four attainment for the poor has been achieved 
Figure 5 Grade four completion, 15-19-year-olds

Poorest $40 \%$ of households

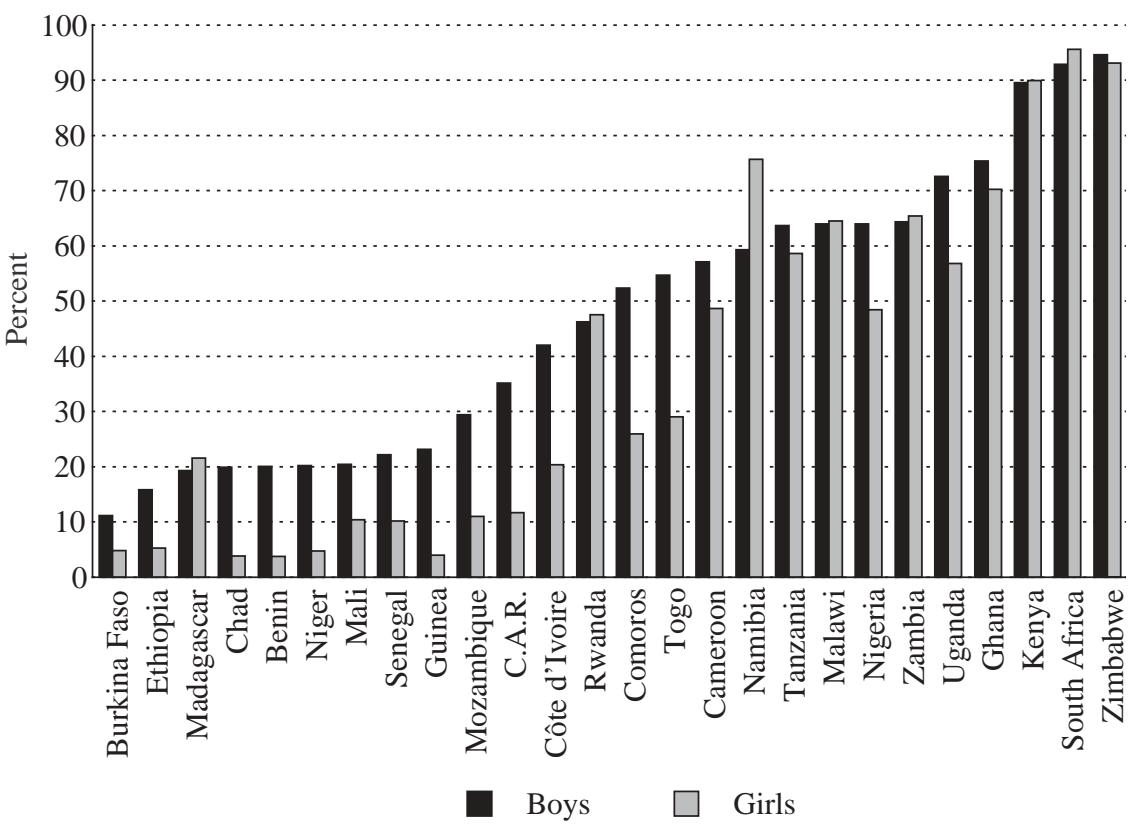

Wealthiest $20 \%$ of households

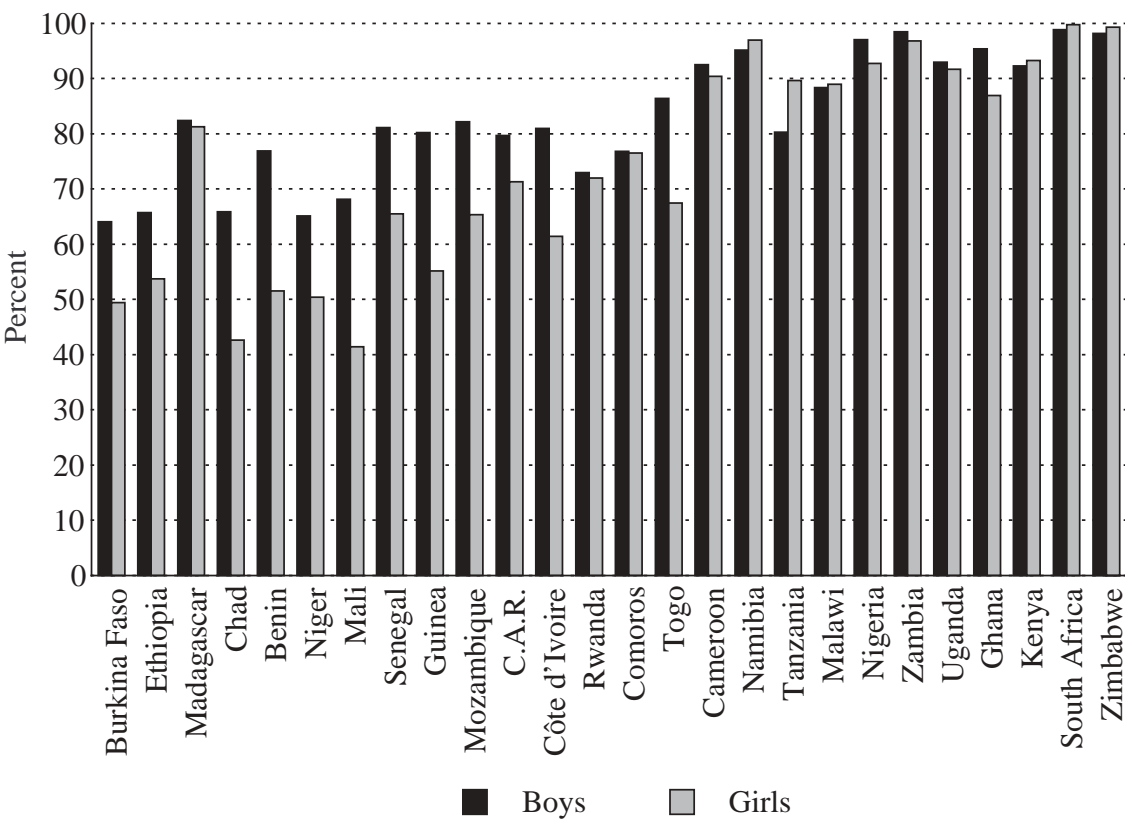

Note: Countries in both panels are listed in ascending order by educational attainment of boys in the poorest 40 percent of households.

Source: DHS data. 
only in Kenya, South Africa, and Zimbabwe for both boys and girls. For the first 11 countries, most of them in Francophone Africa, grade four completion rates for the poor rarely exceed 20 percent for boys or 10 percent for girls. The gender gaps appear larger in countries where grade four attainment for boys is comparatively low. On the other hand, looking at grade four completion rates for the richest 20 percent, many countries have already achieved universal attainment. For many others, such achievement is likely within the next 15 years. For a few countries, however, even the richest 20 percent have far to go. This group includes some of the poorest countries: Burkina Faso, Ethiopia, Chad, Niger, and Mali. While the gender gap among children from the richest households has narrowed or almost disappeared in the majority of countries, this is not the case in much of Francophone Africa, including Burkina Faso, Chad, Benin, Niger, Mali, Senegal, Guinea, Côte d'Ivoire, and Togo. Gender gaps among the rich remain large in Ethiopia and Mozambique as well.

These results suggest that educational reform measures should be tailored to each country's situation and should be based on recent and accurate measures of the performance of different subgroups. At the country level, DHS data permit other breakdowns as well, including provincial and rural/urban breakdowns. While many of these breakdowns could be developed within a well-designed management information system, such would not be the case for household wealth indicators, which require data collected at the household level. Given the enormous financial and organizational mobilization that will be required to achieve the millennium education goals, resources will need to be targeted to the particular population subgroups that are lagging behind. A proper monitoring program will require information on the relative progress of the poor.

\section{CONCLUSIONS}

At the dawn of the twenty-first century we estimate that 37.2 million young adolescents aged 10-14 in sub-Saharan Africa will not complete primary school. This number is nearly twice the entire population of children aged 10-14 in the United States, virtually all of whom will complete primary school. ${ }^{22}$ Reducing the number of uneducated African youth is a primary objective of the United Nations as set forth in the Millennium Development Goal for education (United Nations 2001). Achieving this 
goal will require a level of resources and commitment not previously seen; it will also require better tools for monitoring progress.

We conclude from our assessment of UNESCO's two complementary indicators for monitoring progress toward Education for All that UNESCO data provide at best an incomplete and at worst a biased picture of levels, trends, and gender differences in primary school participation and grade attainment. Part of the problem arises from UNESCO's reliance on disparate management information systems across countries to collate information about children's levels of schooling. This results in the publication of data of variable quality, with limited comparability across countries and over time. The current exclusive reliance of the international community on UNESCO data to track progress toward the millennium goals is misplaced. If there were a more transparent system for collecting schooling information from national ministries, the reliability of UNESCO indicators on a national basis could be evaluated. In the absence of good local management information systems, education data derived from nationally representative surveys fielded on a periodic basis would prove highly useful as an additional, and sometimes alternative, source of data for monitoring progress toward the goal of Education for All.

The Demographic and Health Surveys provide a useful baseline from which to build. Since 2000, household questionnaires have been expanded to allow for the creation of additional schooling indicators, including some that closely parallel commonly used UNESCO indicators. Furthermore, the DHS is beginning to launch in-depth surveys on education in sub-Saharan Africa in conjunction with its regular surveys. The first report has recently been published on Uganda; results for Malawi and Zambia will follow shortly. This effort would require substantial expansion if it were to take on monitoring of educational attainment more broadly.

Even with the limited education data already collected in the traditional DHS surveys, however, much can be learned about past trends and the current status of schooling in sub-Saharan Africa. The trends in primary school completion implied by these data raise questions about the feasibility of achieving the millennium education goal in the foreseeable future. It is even possible some earlier gains could be lost, given recent declines in attendance and attainment among the youngest boys in many countries. It 
also appears that the gap between boys and girls is closing rapidly in all countries despite huge variations in overall levels of educational attainment. Consequently, these findings raise doubts about the likelihood that goals of universal education can be achieved with a strategy limited to an emphasis on girls' schooling.

The education gap between girls and boys has declined largely because of the impressive improvement in schooling for girls in sub-Saharan Africa. Although a large portion of this change occurred decades ago, growth continued in girls' education in the 1980s and 1990s, despite significant economic setbacks. A thorough understanding of the reasons for disparate trends in boys' and girls' education over the past 30 years will require more research. Our data do not allow us to tease out the many possibilities, which might include rising returns to the education of girls (either market or nonmarket), the diffusion of global cultural values relating to the importance of girls' schooling, and the effects of school reform.

Although limits to girls' schooling do not seem to be a major impediment to achieving Education for All, wide disparities remain in schooling by economic status. In short, the schooling gap that remains is the gap between the poorest and wealthiest households. Others have also posited the importance of household wealth vis-à-vis schooling. Filmer and Pritchett (1999) documented the gap in primary school completion rates according to household wealth status using data from many of the DHS surveys available a few years ago. Even earlier, Knodel and Jones (1996), using schooling data from Thailand and Vietnam, raised questions about the heavy emphasis on girls' schooling in the international community given the much wider gaps in schooling by household wealth. This paper offers a new comparison of the size of gender gaps and wealth gaps in most countries of sub-Saharan Africa using several widely accepted schooling indicators. With the gender gap closing in many countries at levels of educational attainment that fall well short of universal primary schooling, new strategies must be devised to reach the poorest parents and their children. 


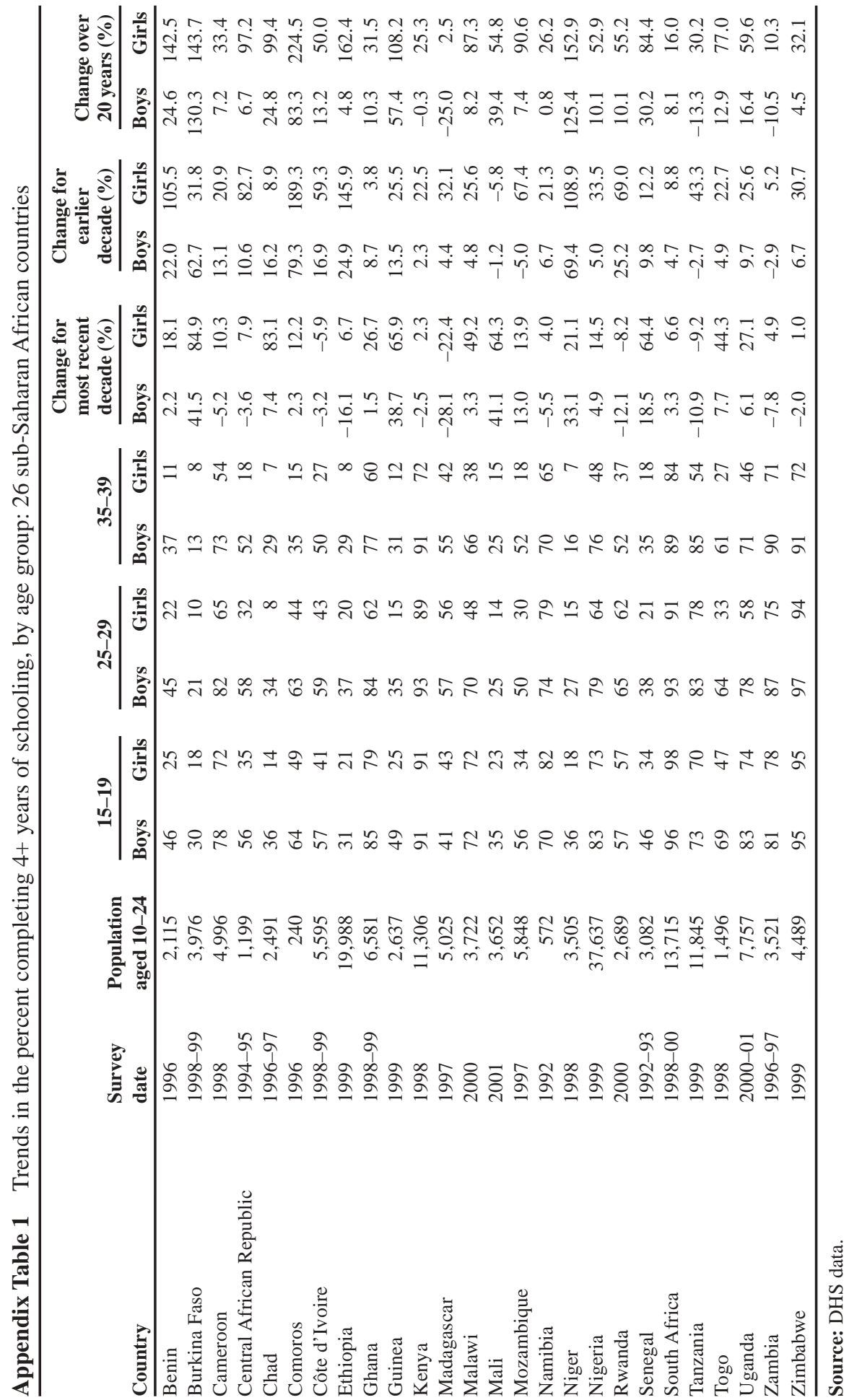




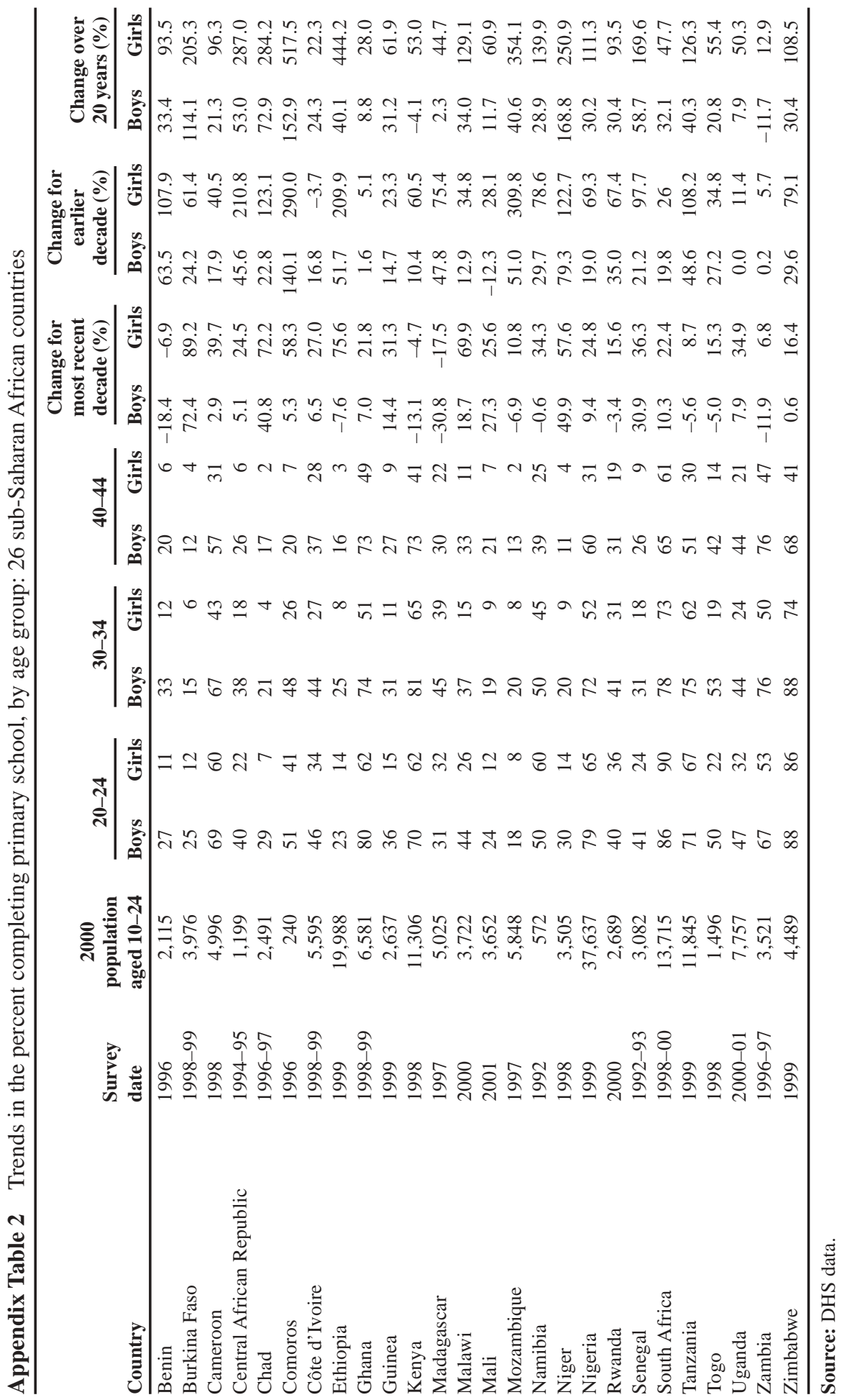




\section{NOTES}

1 These region-wide estimates are based on the assumption that the 17 percent of the sub-Saharan African population that is not represented by DHS data have the same levels of schooling participation and attainment as the 83 percent of the population that is represented (see Table 5). Estimates from Table 5 are multiplied by United Nations population estimates for the region as a whole for the year 2000 to derive the numbers of millions that are in or out of school. These estimates of the out-of-school population are conservative, given that much of the missing population lives in countries that are in the midst of armed conflict and civil disruption.

2 In Malawi and Uganda, recent gains in education are likely due to the abolition of school fees.

3 Data on educational participation and attainment of household members are drawn from a household questionnaire that asks a series of questions about each household member from an informed adult, typically the household head.

4 Among sub-Saharan African countries that have not participated in the DHS survey program since 1990, Angola, Burundi, Congo, Eritrea, Liberia, Sierra Leone, and Somalia have been in the midst of civil unrest or conflict that has made fielding the surveys impossible.

5 These three countries whose surveys were fielded earlier in the 1990s—Central African Republic, Namibia, and Senegal-account for less than 3 percent of the population of young people aged 10-24 in sub-Saharan Africa in 2000 (United Nations 2001).

6 The gross enrollment ratio is a more familiar measure, but it is not clearly interpretable, as it includes in the numerator all children enrolled in school regardless of age and only those in the primary school age range in the denominator. Thus, it often yields values exceeding 100 percent owing to factors such as late entry and grade repetition. For these reasons, its use as a marker for progress is problematic. 
7 There have also been recent changes in some countries in the length of primary school (e.g., in Kenya from eight to seven years and in Malawi from eight to four years: UNESCO 2002).

8 School participation data from the DHS presented in this paper are from responses to the following question on the household survey: "Is ___ [child's name] still in school?" While the UNESCO enrollment ratio measures opening-day enrollments, an attendance ratio from DHS data reflects actual school participation during the stage of the school year when the survey was in the field. It is not entirely clear how this question was interpreted when a household interview took place during the break between school years. In phase III and IV of the DHS surveys, more careful wording was developed so as to measure enrollment in cases where surveys encompassed more than one school year or encompassed a school year and a vacation period. These changes were initiated so that DHS data could become more directly comparable to UNESCO data.

9 Sahn and Stifel (2003) have recently assessed progress toward the millennium development goals in Africa during the 1990s, using attendance rates among 614-year-olds from DHS as their indicator of progress. This is a problematic measure because it ranges over nine age cohorts whereas the net primary enrollment ratio ranges over four to seven years depending on the country. Thus, it is in fact a much higher standard to meet than is required by the millennium goal.

10 Similar findings were highlighted in comparisons between UNESCO's net enrollment ratio and estimates of national attendance ratios using a smaller selection of DHS surveys and a series of UNICEF multiple indicator cluster surveys (Huebler and Loaizia 2002, as cited in UNESCO 2002: 49).

11 It has recently been agreed that the UNESCO Institute of Statistics will alter the existing indicator on cohort survival to grade five. Instead of expressing the number of children entering grade five as a proportion of those who started four years earlier, the estimate will be based on the percentage of the population of grade five age. This will be a proxy for a gross completion rate (UNESCO 2002: 55) 
12 A comparison of trends in retention rates (the proportion of those who ever enter who complete four or more grades) from DHS (not shown) indicates small but steady improvement over time, suggesting that a more contemporaneous measure of retention rates would show even greater discrepancies with the UNESCO survival rate.

13 We chose five-year age cohorts to smooth out variations from smaller sample sizes at individual ages, as well as to deal with some age misreporting in the DHS data.

14 In our assessment of education estimates using two or more DHS surveys, we discovered that although, for many countries, there is a consistency between estimates of educational achievement across surveys, estimates are sometimes inconsistent for those countries with different sampling frames (e.g., Burkina Faso and Nigeria) or differences in the design and implementation of the survey. This assessment involved lining up similar age cohorts across both surveys by indicators of achievement. For example, 20-24-year-olds in a DHS survey for a particular country in 2000 should have the same level of grade four completion as the 15-19-year-olds in a similar DHS survey in 1995. When these estimates line up, within some confidence interval that accounts for sampling error, for a range of age cohorts and indicators, the data can be considered consistent across surveys. Studies that have used two or more surveys to evaluate trends in education (e.g., Sahn and Stifel 2003) have been insensitive to the possibility of noncomparability in the underlying populations sampled. This has resulted in biased conclusions regarding the trends in educational attainment for some countries.

15 We chose not to vary the weights for older cohorts. For a large country with a rapid rate of population growth, such as Ethiopia, its weight in the average is higher than it would otherwise have been for older cohorts. This procedure allows Ethiopia's experience of school progress to be represented on a consistent basis across cohorts.

16 The projection of grade four completion for 10-14-year-olds is estimated by assuming that the average difference, by age cohort, between the percent ever at- 
tending school and the percent completing 4+ years will be maintained. By averaging the differences between indicators across the age cohorts and by subtracting this difference from the percent ever attending school, an estimate of completing $4+$ years for the youngest age cohort can be obtained. A similar estimate can be calculated for completed primary by subtracting the average difference in completed $4+$ years and completed primary from completed $4+$ years. Weights are also used to give the most recent age cohorts a greater influence in determining the average difference. The weights for each observed data point were created by fixing two algebraic conditions, (1) a constant increment between weights and (2) the average of the weights equal to one. Thus, the weights for primary school completion were: $33.67,1.0,1.33$, and 1.67; for grade four completion they were: .29, .57, .86, 1.14, 1.43, and 1.71 .

17 For a more complete discussion of differences in colonial educational regimes, see Lloyd, Kaufman, and Hewett 1999.

18 Botswana, Cameroon, and South Africa are exceptions.

19 Another reason these estimates may be optimistic is that there is evidence for some countries that DHS samples may be better educated relative to the underlying population (Lloyd, Kaufman, and Hewett 2000).

20 This becomes a growing problem as countries decentralize funding as part of educational reform measures. For example, in Tanzania, where funding for primary school shifted from the education ministry to the ministry of local government in 1983, reported educational expenditures dropped dramatically from one year to the next and have since been reported at much lower levels despite the increasing involvement of the ministry of local government in the financing of schools (Samoff and Sumra 1994).

21 This neglects the input of other European donors that may be significant.

22 The estimate for the United States is 20.9 million for July 2001: Table USEST2001-ASRO-CL, National Population Estimates-Characteristics. Population Division, U.S. Census Bureau. 


\section{REFERENCES}

Behrman, J.R. and M.R. Rosenzweig. 1994. "Caveat emptor: Cross-country data on education and the labor force," Journal of Development Economics 44(1): 147171.

Bradshaw, Y.W. and B. Fuller. 1996. "Policy action and school demand in Kenya: When a strong state grows fragile," International Journal of Comparative Sociology 37(1-2): 72-95.

Colclough, C. and S. Al-Samarrai. 2000. "Achieving schooling for all: Budgetary expenditures on education in sub-Saharan Africa and South Asia," World Development 28(11): 1927-1944.

Donors to African Education, I.I.F.E.P. 1994. A Statistical Profile of Education in SubSaharan Africa in the 1980s. Paris: Donors to African Education.

Filmer, D. and L. Pritchett. 1999. "The effect of household wealth on educational attainment: Evidence from 35 countries," Population and Development Review 25(1): 85-120.

Grootaert, C. 1994. "Education, poverty, and structural change in Africa: Lessons from Côte d'Ivoire," International Journal of Educational Development 14(2): 131142.

Hodd, M. 1989. “A survey of the African economies," in S. Moroney (ed.), Handbooks to the Modern World: Africa. New York: Oxford University Press, pp. 787-809.

Kinyanjui, K. 1993. "Enhancing women's participation in the science-based curriculum: The case of Kenya," in J. Ker Conway and S.C. Bourque (eds.), The Politics of Women's Education: Perspectives from Asia, Africa, and Latin America. Ann Arbor, MI: University of Michigan Press, pp. 133-148.

Knodel, J. and G.W. Jones. 1996. "Post-Cairo population policy: Does promoting girls' schooling miss the mark?," Population and Development Review 22(4): 683-702.

Knowles, J.C. and J.R. Behrman. 2003. "Assessing the economic returns to investing in youth in developing countries.” Draft, World Bank.

Lacey, M. 2003. "Primary schools in Kenya, fees abolished, are filled to overflowing," The New York Times (January 7): A8. 
Lloyd, C.B., C.E. Kaufman, and P. Hewett. 1999. "The spread of primary schooling in sub-Saharan Africa: Implications for fertility change," Policy Research Division Working Paper \#127.

Lloyd, C.B., C.E. Kaufman, and P. Hewett. 2000. "The spread of primary schooling in sub-Saharan Africa: Implications for fertility change," Population and Development Review 26(3): 483-515.

Lloyd, C.B., B.S. Mensch, and W.H. Clark. 2000. "The effects of primary school quality on school dropout among Kenyan girls and boys," Comparative Education Review 44(2): 113-147.

Mehrotra, S. and E. Delamonica. 1998. "Household costs and public expenditure on primary education in five low income countries: A comparative analysis," International Journal of Educational Development 18(1): 41-61.

Moulton, J., K. Mundy, M. Welmond, and J. Williams. 2001. "Paradigm lost? The implementation of basic education reforms in sub-Saharan Africa," SD Publication, Series Office of Sustainable Development, Bureau for Africa. Technical Paper No. 109. Washington, DC: USAID.

Nieuwenhuis, F.J. 1996. The Development of Education Systems in Postcolonial Africa: A Study of a Selected Number of African Countries. Pretoria: Human Sciences Research Council Publishers.

Reimers, F. 1994. "Education and structural adjustment in Latin America and sub-Saharan Africa," International Journal of Educational Development 14(2): 119-129.

Sahn, D. E. and D.C. Stifel. 2003. "Progress toward the Millennium Development Goals in Africa," World Development 31(1): 23-52.

Samoff, J. and S. Sumra. 1994. "From planning to marketing: Making education and training policy in Tanzania," in J. Samoff (ed.), Coping with Crisis: Austerity, Adjustment and Human Resources. London and New York: UNESCO and Cassell, pp. 134-172.

Tomasevski, K. 2001. Free and Compulsory Education for All Children: The Gap Between Promise and Performance (Right to Education Primers No. 2). Lund and 
Stockholm, Sweden: Raoul Wallenberg Institute and Swedish International Development Cooperation Agency (SIDA).

UNESCO. 2002. "Education for all: Is the world on track?," EFA Global Monitoring Report 2002. Paris: UNESCO Publishing.

United Nations. 2001. World Population Prospects: The 2000 Revision. Vol. 1: Comprehensive Tables. New York: United Nations Department of Economic and Social Affairs, Population Division.

United Nations General Assembly. 2001. "Road map towards the implementation of the United Nations Millennium Declaration," Report of the Secretary-General. New York: United Nations Department of Public Information.

World Bank. 1988. Education in Sub-Saharan Africa: Policies for Adjustment, Revitalization, and Expansion. Washington, DC: World Bank.

World Bank. 2002. World Development Indicators. 


\title{
POLICY RESEARCH DIVISION WORKING PAPERS
}

\author{
Recent Back Issues
}

144 John Bongaarts, "Household size and composition in the developing world."

145 John B. Casterline, Zeba A. Sathar, and Minhaj ul Haque, "Obstacles to contraceptive use in Pakistan: A study in Punjab."

146 Zachary Zimmer, Albert I. Hermalin, and Hui-Sheng Lin, "Whose education counts? The impact of grown children's education on the physical functioning of their parents in Taiwan."

147 Philomena Nyarko, Brian Pence, and Cornelius Debpuur, "Immunization status and child survival in rural Ghana."

*148 John Bongaarts and Zachary Zimmer, "Living arrangements of older adults in the developing world: An analysis of DHS household surveys."

149 Markos Ezra, "Ecological degradation, rural poverty, and migration in Ethiopia: A contextual analysis."
150 Cynthia B. Lloyd, Sahar El Tawila, Wesley H. Clark, and Barbara S. Mensch, "Determinants of educational attainment among adolescents in Egypt: Does school quality make a difference?"

151 Barbara S. Mensch, Paul C. Hewett, and Annabel Erulkar, "The reporting of sensitive behavior among adolescents: A methodological experiment in Kenya."

152 John Bongaarts, "The end of the fertility transition in the developed world."

153 Mark R. Montgomery, GebreEgziabher Kiros, Dominic Agyeman, John B. Casterline, Peter Aglobitse, and Paul Hewett, "Social networks and contraceptive dynamics in southern Ghana."

*154 Paul C. Hewett and Mark R. Montgomery, "Poverty and public services in developing-country cities."

* No longer available 
155 Zachary Zimmer, Linda G. Martin, and Ming-Cheng Chang, "Changes in functional limitations and survival among the elderly in Taiwan: 1993, 1996, and 1999."

156 John Bongaarts and Griffith Feeney, "How long do we live?"

157 Zachary Zimmer and Sovan Kiry Kim, "Living arrangements and socio-demographic conditions of older adults in Cambodia."

158 Geoffrey McNicoll, "Demographic factors in East Asian regional integration."

159 Carol E. Kaufman, Shelley Clark, Ntsiki Manzini, and Julian May, "How community structures of time and opportunity shape adolescent sexual behavior in South Africa."

*160 Julia Dayton and Martha Ainsworth, "The elderly and AIDS: Coping strategies and health consequences in rural Tanzania."

161 John Bongaarts, "The end of the fertility transition in the developing world."
162 Naomi Rutenberg, Carol E. Kaufman, Kate Macintyre, Lisanne Brown, and Ali Karim, "Pregnant or positive: Adolescent childbearing and HIV risk in South Africa."

163 Barbara S. Mensch, Wesley H. Clark, and Dang Nguyen Anh, "Premarital sex in Vietnam: Is the current concern with adolescent reproductive health warranted?"

164 Cynthia B. Lloyd, Cem Mete, and Zeba A. Sathar, "The effect of gender differences in primary school access, type, and quality on the decision to enroll in rural Pakistan."

165 Kelly Hallman, Agnes R. Quisumbing, Marie Ruel, and Bénédicte de la Brière, "Childcare, mothers' work, and earnings: Findings from the urban slums of Guatemala City."

*166 Carol E. Kaufman and Stavros E. Stavrou, "Bus fare, please': The economics of sex and gifts among adolescents in urban South Africa."

*167 Dominic K. Agyeman and John B. Casterline, "Social organization and reproductive behavior in southern Ghana."

* No longer available 
168 Paul C. Hewett, Annabel S. Erulkar, and Barbara S. Mensch, "The feasibility of computer-assisted survey interviewing in Africa: Experience from two rural districts in Kenya."

169 Zachary Zimmer and Julia Dayton, "The living arrangements of older adults in sub-Saharan Africa in a time of HIV/AIDS."

170 Ravai Marindo, Steve Pearson, and John B. Casterline, "Condom use and abstinence among unmarried young people in Zimbabwe: Which strategy, whose agenda?"

171 Sajeda Amin and Nagah H. AlBassusi, "Wage work and marriage: Perspectives of Egyptian working women."

172 Zachary Zimmer, Napaporn Chayovan, Hui-Sheng Lin, and Josefina Natividad, "How indicators of socioeconomic status relate to physical functioning of older adults in three Asian societies."
173 Paul Demeny, "Population policy: A concise summary."

174 Geoffrey McNicoll, "Population and development: An introductory view."

175 James F. Phillips, Tanya C. Jones, Frank K. Nyonator, and Shruti Ravikumar, "Evidence-based development of health and family planning programs in Bangladesh and Ghana."

176 Cynthia B. Lloyd and Paul C. Hewett, "Primary schooling in sub-Saharan Africa: Recent trends and current challenges." 